Journal of

Women's Health and Gynecology

\title{
Comparing the Effects of Tranexamic Acid and Medroxyprogestrone on Puerperal Bleeding
}

\author{
Firoozeh Veisi*, Maryam Zangeneh, Negin Rezavand, Elahe Sharifi
}

Department of obstetrics and gynecology, High Risk Pregnancy Research Center, Imam Reza Hospital, Kermanshah University of Medical Sciences, Kermanshah, Iran

*Corresponding author: Firoozeh Veisi, Gynecologist and Obstetrician, High Risk Pregnancy Research Center, Imam Reza Hospital, Kermanshah University of Medical Sciences, Kermanshah, Iran, Email: firoozehveisi@yahoo. com

Received Date: April 15, 2015 Accepted Date: March 04, 2015 Published Date: March 08, 2015

Citation: Firoozeh Veisi(2015) Comparing the Effects of Tranexamic Acid and Medroxyprogestrone on Puerperal Bleeding . J Womens Health Gyn 2: 1-4

\section{Abstract}

Introduction: The aim of this study was to compare the effects of tranexamic acid and medroxyprogestrone on puerperal bleeding.

Materials and Methods: In this double-blind clinical trial, 66 female patients aged 15-45 years were selected by convenience sampling and divided two groups. The patients of group A, tranexamic acid $250 \mathrm{mg}$ capsule were given every 12 hours with two ferrous sulfate $325 \mathrm{mg}$ tablets. In group B, medroxyprogesterone $5 \mathrm{mg}$ tablet were given every 12 hours with two ferrous sulfate $325 \mathrm{mg}$ tablets. After 6 weeks of treatment, the patients were re-evaluated about the study outcomes included bleeding, hemoglobin levels, adverse effects and re-intervention. Collected data were analyzed by SPSS-18 and chi-square and $t$ tests.

Results: After 6 weeks of starting treatment, the bleeding in both groups reduced and hemoglobin levels increased. The bleeding days in TXA group was significantly reduced more than MP group $(\mathrm{P}=0.001)$, but no significant differences were observed between two group in hemoglobin levels and the number of pads used in bleeding days $(\mathrm{P}>0.05)$. The side effects of TXA in patients were significantly lower than MP users $(\mathrm{P}<0.0001)$. The satisfaction of patients treated with TXA also were significantly greater than patients treated with $\mathrm{MP}(90.9 \%$ vs. $60.6 \%)(\mathrm{P}=0.008)$.

Conclusions: The results showed that TXA significantly reduced the amount of puerperal bleeding compared to MP. The adverse effects of TXA are non-serious and significantly lower than MP.

Keywords: Tranexamic Acid; Medroxyprogestrone; Puerperal Bleeding

\section{Introduction}

Postpartum hemorrhage $(\mathrm{PPH})$ is a major cause of maternal mortality (300000 deaths per year in the world) and morbidity such as anemia, blood transfusions and organ ischemia [1]. Secondary PPH or puerperal hemorrhage refers to excessive uterine bleeding occurring between 24 hours and 12 weeks postpartum. It affects 0.5 to 2 percent of women in developed countries [2,3]. The causes of PPH are uterine atony, trauma, retained placenta, and coagulopathy [4].

Prolonged PPH can cause anemia, dizziness and impaired sexual activity after delivery. The total duration of lochia is 27-30 days after delivery that up to 7 to 14 days may be related to lochia rubra, but in but in some cases, the bleeding takes longer or the amount is heavier [5-7].

Different strategies have been used for the treatment of PPH that one of them is use of tranexamic acid. Tranexamic acid (TXA) is a synthetic anti-fibrinolytic drug that acts through inhibiting lysine binding to plasmin and plasminogen $[8,9]$. This drug can reduce bleeding and blood transfusion requirements for various surgical procedures [10]. TXA has been used for the treatment of heavy menstrual bleeding and good results were obtained. It has caused satisfying the women with severe bleeding and improved the quality of life [11-14]. A study of patients with severe men- 
strual bleeding treated with TXA, showed that three months after administration, $80 \%$ improvement in quality of life were observed [15]. The side effects such as nausea and vomiting caused by using TXA or thromboembolic events are more than normal people. The drug is excreted very low in breast milk and has not any effect on baby [16].

Hormonal management is first-line medical therapy for patients with acute abnormal uterine bleeding $[17,18]$ However, there is no consistency among the hormonal regimens recommended and very little or no scientific evidence of efficacy for any of them. The use of hormonal drugs such as OCP for PPH is not appropriate, because it reduces the quality and quantity of breast milk [16]. Medroxyprogestrone (MP) is a steroidal progestin drug used for treating PPH. In females, MP is used as an oral or depot-injected contraceptive and also as the progestin component of menopausal hormone replacement therapy to prevent endometrial hyperplasia and cancer. It's also used as a treatment for endometriosis, dysmenorrhea and amenorrhea $[19,20]$.

No study has been done to show the effect of MP and TXA on puerperal hemorrhage. Previous studies have investigated the effects of injectable drugs in emergency obstetric hemorrhage until 24 hours after delivery. Therefore, this study was conducted to compare the effects of tranexamic acid and medroxyprogestrone on puerperal bleeding.

\section{Materials \& Methods}

In this double-blind clinical trial, 66 female patients aged 15-45 years referred to outpatient clinic of Imam Reza Hospital (Kermanshah, Iran) with prolonged PPH or severe bleeding after delivery were selected by convenience sampling and were enrolled after obtaining written informed consent. The amount of bleeding in patients was at levels that cause discomfort and referring to the hospital for treatment. All patients underwent exact gynecological examination. The patients were divided two groups (A \& B) with random allocation and a ratio of one to one. The patients of group A, tranexamic acid 250 mg capsule were given every 12 hours with two ferrous sulfate $325 \mathrm{mg}$ tablets. In group B, medroxyprogesterone $5 \mathrm{mg}$ tablet were given every 12 hours with two ferrous sulfate $325 \mathrm{mg}$ tablets. All medications were prepared from Aburaihan pharmaceutical company (Tehran, Iran). Before taking the medications, hemoglobin $(\mathrm{Hb})$ levels were measured for all patients. Patients selected by a resident of gynecology and the medication were given to the patients by a nurse that none of them were unaware of the type of drug and how to prescribe it to patients. Study duration and follow-up since the beginning of the intervention was about 6 weeks. after 6 weeks of treatment, the patients were visited again and the primary outcomes included bleeding (based on number of bleeding days and number of pads used in bleeding days) and hemoglobin levels and secondary outcomes included adverse effects (Nausea/Vomiting, spotting and gastrointestinal discomfort) and re-intervention were assessed. At the end of 6th week, in general, the patients were asked whether they consent or not this type of therapy?

The inclusion criteria were included 15-45 years old women with prolonged puerperal bleeding, dizziness, low blood pressure, skin irritation caused by using pads and at least 30 days after delivery, and the exclusion criteria were included the birth canal rupture, placental debris, myoma and endometrial polyps, chronic disease such as liver or kidney diseases, diabetes mellitus, coagulopathy and thromboembolic events, using anticoagulation medications and low platelet.

Collected data were analyzed by SPSS-18 statistical software and chi-square and t tests. A significance level of 0.05 was considered for all tests.

\section{Results}

A total of 66 patients with puerperal bleeding in groups A and B were treated with TXA and MP and their outcomes were compared together. The results of comparing the quantitative variables included age, height and weight of the patients have been shown in table 1 . The results showed that there were no significant differences between two group in age, height, weight, gestational age and parity $(\mathrm{P}>0.05)$. In group $\mathrm{A}$, 11 patients $(33.3 \%)$ had a normal vaginal delivery (NVD) and 22 patients $(66.7 \%)$ had cesarean section (CS), and in group B, 13 patients (39.4\%) had NVD and 20 patients $(60.6 \%)$ had CS $(\mathrm{P}>0.05)$.

\begin{tabular}{|c|c|c|c|}
\hline \multirow{2}{*}{ Group } & $\begin{array}{c}\mathbf{A} \\
(\mathrm{n}=33)\end{array}$ & $\begin{array}{c}\mathbf{B} \\
(\mathrm{n}=33)\end{array}$ & \multirow{2}{*}{ P value } \\
\cline { 2 - 3 } & $\mu \pm \mathrm{sd}$ & $\mu \pm \mathrm{sd}$ & \\
\hline Age $($ year $)$ & $27.3 \pm 5.6$ & $27.6 \pm 5.9$ & 0.83 \\
\hline Height $(\mathrm{m})$ & $1.61 \pm 3.88$ & $1.61 \pm 4.27$ & 0.72 \\
\hline Weight $(\mathrm{kg})$ & $69.3 \pm 5.4$ & $71.0 \pm 6.9$ & 0.26 \\
\hline
\end{tabular}

Table : Distribution of the quantitative variables in two study groupsdidactic sessions

Evaluating the parameters related to bleeding before starting treatment showed that there are no significant differences between groups A and B in hemoglobin levels, number of bleeding days and number of pads used in bleeding days $(\mathrm{P}>0.05)$ (Table 2).

\begin{tabular}{|c|c|c|c|}
\hline Group & $\begin{array}{c}\text { A } \\
(\mathrm{n}=33)\end{array}$ & $\begin{array}{c}\text { B } \\
(\mathrm{n}=33)\end{array}$ & \multirow{2}{*}{ P value } \\
\cline { 2 - 3 } & $\mu \pm \mathrm{sd}$ & $\mu \pm \mathrm{sd}$ & \\
\hline Variable & $11.8 \pm 0.9$ & $11.8 \pm 0.8$ & 0.93 \\
\hline Height $(\mathrm{m})$ & $45.3 \pm 7.3$ & $42.7 \pm 5.3$ & 0.10 \\
\hline Weight $(\mathrm{kg})$ & $2.4 \pm 0.66$ & $2.5 \pm 0.5$ & 0.40 \\
\hline
\end{tabular}

Table 2 : First evaluation of the parameters related to puerperal bleeding in two study groups

Assessment of the response to treatment after 6 weeks showed that number of bleeding days between two groups was significantly different $(\mathrm{P}=0.001)$, but no significant differences between two groups were found regarding $\mathrm{Hb}$ levels and the number of pads used in bleeding days $(\mathrm{P}>0.05)$ (Table 3 ).

It was found that after 6 weeks of starting treatment, 2 patients $(6.0 \%)$ in group $A$ and 2 patients $(6.0 \%)$ in group B were still bleeding. In group A, 5 patients (15.2\%) had spotting, 3 patients $(9.0 \%)$ had nausea/vomiting, 9 patients $(27.3 \%)$ had gastrointestinal discomfort and 14 patients $(42.4 \%)$ were without complaints. In group B, 22 patients (66.7\%) had spotting and $9(27.3 \%)$ patients were without complaints, and none of them had nausea/vomiting or gastrointestinal discomfort. 
The patient satisfaction with treatment in groups A and B was 90.9\% (30 patients) and 60.6\% (20 patients), respectively. A total of 7 patients $(21.2 \%)$ in group A and 9 patients $(27.3 \%)$ in group $\mathrm{B}$ were required to re-intervention $(\mathrm{P}>0.05)$.

\begin{tabular}{|c|c|c|c|}
\hline \multirow{2}{*}{ Group } & $\begin{array}{c}\text { A } \\
(\mathrm{n}=33)\end{array}$ & $\begin{array}{c}\text { B } \\
(\mathrm{n}=33)\end{array}$ & \multirow{2}{*}{ P value } \\
\cline { 2 - 3 } & $\mu \pm \mathrm{sd}$ & $\mu \pm \mathrm{sd}$ & \\
\hline $\mathrm{Hb}$ & $12.2 \pm 0.7$ & $12.1 \pm 0.7$ & 0.80 \\
\hline Bleeding days & $9.8 \pm 10.4$ & $19.0 \pm 11.0$ & 0.001 \\
\hline Number of Pads & $0.2 \pm 0.6$ & $0.3 \pm 0.5$ & 0.65 \\
\hline
\end{tabular}

Table 3 : Second evaluation of the parameters related to puerperal bleeding in two study groups

Analysis of data showed that there was a significant difference between two groups in terms of the complaints due to adverse effects of the medications $(\mathrm{P}<0.0001)$, and the satisfaction of patients with treatment $(\mathrm{P}=0.008)$.

\section{Discussion}

Comparing the patients with puerperal bleeding after 6 weeks of treatment showed that TXA significantly reduced the number of bleeding days in patients than MP group, but no significant differences were observed in hemoglobin levels and the number of pads used in bleeding days, which can be due to the relatively small sample size of this study. However, in both groups, treatment increased hemoglobin levels, reduced the number of bleeding days and number of used pads. In addition, the side effects of TXA in patients were significantly lower than MP users, so that patients in group MP suffered from spotting more than 4 times of TXA group $(66.7 \%$ vs. $15.2 \%)$. Despite the complaints of nausea and vomiting and gastrointestinal discomfort in patients treated with TXA, none of the patients in group MP had gastrointestinal complaints. The satisfaction of patients treated with TXA also was significantly greater than patients treated with MP (90.9\% vs. $60.6 \%)$. The need for re-intervention was not significantly different between TXA and MP groups.

Other researchers have also found similar or different results in their studies. There are several studies in which TXA is used to control bleeding after delivery. Ducloy-Bouthors, et al. [21] used high dose of TXA for PPH and found that the amount of blood and $\mathrm{Hb}$ loss was decreased [21]. In the present study also TXA significantly reduced puerperal bleeding in the women and $\mathrm{Hb}$ levels increased after treatment, although the increase was not significant. Sekhavat, et al. [22] in their study used TXA immediately before CS in pregnant women and showed that bleeding was reduced until two hours after CS and the Hb levels at 24 hours after surgery were higher than control group [22]. Ferrer, et al. [23] in their systematic review of using TXA to control PPH concluded TXA may reduce bleeding after delivery, but further studies are needed to prove this effect [23]. The present study as the above studies achieved to the positive results about the effects of TXA to decrease PPH and puerperal bleeding. Philipp, et al. [14] in their study on the women with menorrhagia demonstrated that a greater reduction in menstrual blood flow with TXA compared to placebo, non-steroidal anti-inflammatory agents and progesterone. In addition, in women with menorrhagia and an underlying bleeding disorder, TXA was compared to intranasal desmopressin and also demonstrated a greater reduction in menstrual blood flow [14]. In the study of Zhang, et al. [24] was observed that the regimen of TXA during menstrual days 1-5 is a more effective and tolerable treatment than luteal phase norethisterone for patients with ovulatory menorrhagia [24]. Although menstrual bleeding not investigated in the present study, but the effect of TXA on reducing the amount of puerperal bleeding was confirmed. The results of Shakur's study on the women with PPH showed that intravenous TXA reduced uterine bleeding, hysterectomy, and mortality [25]. Kriplani, et al. [26] in their study concluded that TXA in the treatment of nonfunctional uterine bleeding is better than medroxyprogesterone acetate (MPA) in safety and efficacy [26]. In this study, puerperal bleeding in patients treated with TXA had significant reduction compared with MP. The study of Goshtasebi, et al. [27] on comparing the effects of TXA with MPA in the treatment of heavy menstrual bleeding of endometrial origin showed that duration of bleeding and $\mathrm{Hb}$ values as well as quality of life were significantly improved in both groups, But there was no significant deference between groups. More drug complication and less satisfaction were reported by MPA group [27]. In the present study, puerperal bleeding and $\mathrm{Hb}$ levels were significantly improved in both groups and this improvement in group TXA was significantly greater than group MP. As the above study, the adverse effects of MP were significantly higher than TXA. Lukes, et al. [13] in their study concluded the oral tranexamic acid treatment was well tolerated and significantly improved both menstrual blood loss and health-related quality of life in women with heavy menstrual bleeding [13]. Senthong and Taneepanichskul [28] showed that TXA was more effective than placebo in short-term treatment of irregular uterine bleeding/spotting associated with DMPA use [28], that confirmed the findings of present study. Phupong, et al (2006) TXA for 5 days appears to be an effective treatment for irregular uterine bleeding associated with Norplant use [29].

The present study following further studies by other researchers showed that as TXA reduced menstrual bleeding and $\mathrm{PPH}$ and after the first 24 hours after delivery, it significantly reduced puerperal bleeding which the effect is considerably more in comparison with other drugs such as MP. In addition, low side effects of TXA and patient satisfaction with treatment demonstrated use it as a first-line treatment of puerperal bleeding. However, confirming the efficacy and safety of TXA in comparison with other treatments require further studies.

\section{Conclusion}

The results showed that TXA significantly reduced the amount of puerperal bleeding compared to MP. The adverse effects of TXA are non-serious and significantly lower than MP. The satisfaction of patients treated with TXA was significantly greater than MP users, but the need for re-intervention was not significantly different between two groups. Thus, TXA can be used safely and effectively in women undergoing puerperal bleeding. 


\section{References}

1) Hogan MC, Foreman KJ, Naghavi M, Ahn SY, Wang M, et al. (2010) Maternal mortality for 181 countries, 1980-2008: a systematic analysis of progress towards Millennium Development Goal 5. Lancet 375: 1609-1623.

2) Alexander J, Thomas P, Sanghera J (2002) Treatments for secondary postpartum haemorrhage. Cochrane Database Syst Rev: CD002867.

3) Hoveyda F, MacKenzie IZ (2001) Secondary postpartum haemorrhage: incidence, morbidity and current management. BJOG 2001: 108: 927.

4) Anderson JM, Etches D (2007) Prevention and management of postpartum hemorrhage. Am Fam Physician 75: 875-82.

5) Oppenheimer LW, Sherriff EA, Goodman JD, Shah D, James CE (1986) The duration of lochia. Br J Obstet Gynaecol 93: 754-757.

6) Elsedeek MS (2012) Puerperal and menstrual bleeding patterns with different types of contraceptive device fitted during elective cesarean delivery. Int J Gynaecol Obstet 116: 31-34.

7) Marchant S, Alexander J, Garcia J, Ashurst H, Alderdice F, et al. (1999) A survey of women's experiences of vaginal loss from 24 hours to three months after childbirth (the BLiPP study). Midwifery 15: 7281 .

8) Longstaff C (1994) Studies on the mechanisms of action of aprotinin and tranexamic acid as plasmin inhibitors and antifibrinolytic agents. Blood Coagul Fibrinolysis 5: 537-542.

9) Hoylaerts M, Lijnen HR, Collen D (1981) Studies on the mechanism of the antifibrinolytic action of tranexamic acid. Biochim Biophys Acta 67: 673: 75-85.

10) Henry DA, Carless PA, Moxey AJ, O’Connell D, Stokes BJ, et al. (2007) Anti-fibrinolytic use for minimising perioperative allogeneic blood transfusion. Cochrane Database Syst Rev 1: CD001886.

11)Bonnar J, Sheppard BL (1996) Treatment of menorrhagia during menstruation: randomised controlled trial of ethamsylate, mefenamic acid, and tranexamic acid. BMJ $313: 579-582$.

12) Srinil S, Jaisamrarn U (2005) Treatment of idiopathic menorrhagia with tranexamic acidJ Med Assoc Thai 88 (suppl 2): s1-s6.

13) Lukes AS1, Moore KA, Muse KN, Gersten JK, Hecht BR, et al. (2010) Tranexamic acid treatment for heavy menstrual bleeding: a randomized controlled trial. Obstet Gynecol 116 : 865-875.

14) Philipp CS (2011) Antifibrinolytics in women with menorrhagia. Thromb Res 127 (Suppl 3): S113-115.

15) Winkler UH (2001) The effect of tranexamic acid on the quality of life of women with heavy menstrual bleeding. Eur J Obstet Gynecol Reprod Biol; 99: 238-243.

16) Dunn CJ, Goa KL (1999) Tranexamic acid: a review of its use in surgery and other indications. Drugs 57: 1005-1032.

17) American College of Obstetricians and Gynecologists (2013) ACOG committee opinion no. 557: Management of acute abnormal uterine bleeding in nonpregnant reproductive-aged women. Obstet Gynecol $121: 891-896$.

18) James AH, Kouides PA, Abdul-Kadir R, Dietrich JE, et al. (2011) Evaluation and management of acute menorrhagia in women with and without underlying bleeding disorders: consensus from an international expert panel. Eur J Obstet Gynecol Reprod Biol 158: 124134.

19) Panay N, Fenton A (2010) Bioidentical hormones: what is all the hype about? Climacteric 13: 1-3.

20) Furness S, Roberts H, Marjoribanks J, Lethaby A, Hickey M, et al. (2009) Hormone therapy in postmenopausal women and risk of endometrial hyperplasia”. Cochrane Menstrual Disorders and Subfertility Group 2: CD000402.

21) Ducloy-Bouthors AS, Jude B, Duhamel A, Broisin F, et al. (2011) High-dose tranexamic acid reduces blood loss in postpartum haemorrhage. Crit Care 15: R117.

22) Sekhavat L, Tabatabaii A, Dalili M, Farajkhoda T, Tafti AD (2009) Efficacy of tranexamic acid in reducing blood loss after cesarean section. J Matern Fetal Neonatal Med 22: 72-75.

23) Ferrer P, Roberts I, Sydenham E, Blackhall K, Shakur H (2009) Anti-fibrinolytic agents in post partum haemorrhage: a systematic review. BMC Pregnancy Childbirth 15: 9-29.

24) Zhang YW, He FF, Sun ZY, Li SW, Bi SL, et al. (2008) [A multicenter prospective randomized open comparative study on the treatment of ovulatory menorrhagia with tranexamic acid and norethisterone in China]. 43: 247-250.

25) Shakur H, Elbourne D, Gülmezoglu M, Alfirevic Z, Ronsmans C, et al. (2010) The WOMAN Trial (World Maternal Antifibrinolytic Trial): tranexamic acid for the treatment of postpartum haemorrhage: an international randomised, double blind placebo controlled trial. Trials 11: 40.

26) Kriplani A, Kulshrestha V, Agarwal N, Diwakar S (2006) Role of tranexamic acid in management of dysfunctional uterine bleeding in comparison with medroxyprogesterone acetate. J Obstet Gynaecol 26: 673-678.

27) Goshtasebi A, Moukhah S, Gandevani SB (2013) Treatment of heavy menstrual bleeding of endometrial origin: randomized controlled trial of medroxyprogesterone acetate and tranexamic acid. Arch Gynecol Obstet 288: 1055-1060.

28) Senthong AJ, Taneepanichskul S (2009) The effect of tranexamic acid for treatment irregular uterine bleeding secondary to DMPA use. J Med Assoc Thai 92: 461-465.

29) Phupong V, Sophonsritsuk A, Taneepanichskul S (2006) The effect of tranexamic acid for treatment of irregular uterine bleeding secondary to Norplant use. 73: 253-256.

Submit your manuscript to a JScholar journal and benefit from:

ब Convenient online submission

ฯ Rigorous peer review

I Immediate publication on acceptance

ฯ Open access: articles freely available online

q High visibility within the field

ๆ Better discount for your subsequent articles

Submit your manuscript at

http://www.jscholaronline.org/submit-manuscript.php 